\title{
Yolk sac tumor in the abdominal wall of an 18-month-old girl: a case report
}

\author{
Machiel van den Akker ${ }^{1,5^{*}}$ (D), Dirk Vervloessem ${ }^{2}$, An Huybrechs $^{3}$, Sabine Declercq ${ }^{4}$ and Jutte van der Werff ten Bosch ${ }^{5}$
}

\begin{abstract}
Background: Pediatric germ cell tumors account for approximately $3.5 \%$ of all childhood cancers for children under the age of 15 years. Up to one-third are extragonadal neoplasms. Germ cell tumors are a heterogeneous group of malignant tumors with a wide variety of histopathological features. Yolk sac tumor is the predominant variant in newborns and younger children. We report for the first time, the presentation of a primary yolk sac tumor in the abdominal wall of a small child.

Case presentation: An 18-month-old white girl underwent resection of a small, round subcutaneous lump $(1.5 \times 1$. $3 \times 0.8 \mathrm{~cm}$ ) of the abdominal wall in her right hypochondriac region. The histopathology was compatible with yolk sac tumor. Her alpha-fetoprotein was initially elevated but normalized after the resection. Magnetic resonance imaging of her abdomen was normal. The surgeon decided to observe and follow her alpha-fetoprotein level closely. One year after resection a local recurrence appeared and her alpha-fetoprotein rose to $58 \mathrm{ng} / \mathrm{mL}$. The surgeon performed a wide resection of the lesion with normalization of her alpha-fetoprotein. Follow-up consisted of measuring alpha-fetoprotein, clinical evaluation, and abdominal ultrasound.
\end{abstract}

Conclusions: Clinicians should be aware that a yolk sac tumor can present in an unusual extragonadal place, for example in this case it was subcutaneous. In some cases, conservative treatment can be carried out with careful monitoring of the patient and their alpha-fetoprotein.

Keywords: Case report, Extragonadal germ cell tumor, Yolk sac tumor, Skin tumor, Children, Alpha-fetoprotein

\section{Background}

Pediatric germ cell tumors (GCTs) account for approximately $3.5 \%$ of all childhood cancers for children under the age of 15 years. Between the ages 15 and 19 the frequency goes up to $16 \%$. Up to one-third are extragonadal neoplasms and the most common sites are the sacrococcygeal or retroperitoneal region, and the pineal gland. The incidence of extragonadal tumors varies widely by age (higher in younger age) and gender (more often in girls at a younger age, while intracranial/intraspinal tumors are more common in boys at an older age) [1].

The only known risk factor for extragonadal GCTs is the presence of Klinefelter syndrome (47,XXY karyotype). In that case, there is a 50 -fold increased risk of developing mediastinal GCTs in early adolescence $[2,3]$.

\footnotetext{
* Correspondence: machielvdakker@gmail.com

'Department of Pediatrics, ZNA Queen Paola Children's Hospital, Antwerp, Belgium

${ }^{5}$ Department of Pediatric Hematology Oncology, UZ Brussel, Jette, Belgium Full list of author information is available at the end of the article
}

GCTs are a heterogeneous group of malignant tumors with a wide variety of histopathological features. Yolk sac tumor is the predominant variant in newborns and younger children, while later in life a wide range of histologic subtypes are seen. Yolk sac tumors have a microcystic reticular pattern and are cytokeratinpositive. Alpha-fetoprotein ( $\alpha \mathrm{FP})$ expression is characteristic and can be used for diagnosis and monitoring of therapy. To the best of our knowledge, this is the first report of the presentation of a primary yolk sac tumor in the abdominal wall of a small child. After resection of the tumor, close monitoring was conducted, without any adjuvant chemotherapy.

\section{Case presentation}

An 18-month-old white girl underwent resection of a small, round subcutaneous lump $(1.5 \times 1.3 \times 0.8 \mathrm{~cm})$ of the abdominal wall in her right hypochondriac region. The tumor was connected to her skin and had the macroscopic appearance of a pilomatrixoma (epithelioma of 
Malherbe). Surprisingly the histopathology was compatible with yolk sac tumor, showing a microcystic reticular pattern (Fig. 1) with positive staining for cytokeratin 8 as well as cytoplasmic granular staining of $\alpha \mathrm{FP}$ (Fig. 2). The resection borders were not completely clear from tumor tissue: stage II according to the Pediatric Oncology Group (POG)/Children's Cancer Study Group (CCG) staging for malignant extragonadal GCT [4]. Her $\alpha \mathrm{FP}$ was $57 \mathrm{ng} / \mathrm{mL} 3$ weeks after resection and dropped to 15 $\mathrm{ng} / \mathrm{mL} 1$ month later; her beta subunit of human chorionic gonadotropin (BHCG) was normal. An magnetic resonance imaging (MRI) of her abdomen was normal. The surgeon decided to observe and follow our patient's $\alpha \mathrm{FP}$ closely because of the lack of radiological evidence of the presence of a tumor and the decline in her $\alpha \mathrm{FP}$. Her $\alpha F P$ remained stable in the first months. One year after resection a local recurrence $(1.1 \mathrm{~cm}$, Fig. 3) appeared with an increase in her $\alpha \mathrm{FP}$ to $29 \mathrm{ng} / \mathrm{mL}$. An MRI of her head, neck, thorax, and abdomen did not show any other masses. The surgeon performed a wide resection of the lesion. The pathology report confirmed the previous findings; the borders were free of tumor tissue. Because the tumor was completely removed with normalization of her $\alpha \mathrm{FP}$ (on the day of surgery her $\alpha \mathrm{FP}$ was $58 \mathrm{ng} / \mathrm{mL}, 10$ days later $12 \mathrm{ng} / \mathrm{mL}, 1$ month postoperative $8 \mathrm{ng} / \mathrm{mL}$ ) and there was no evidence of any other tumor masses, the management was expectative. The first year post-resection was uneventful without clinical signs of local recurrence and with normal monthly $\alpha F P$ level. An abdominal ultrasound, 1 year after resection, did not reveal a recurrence. Follow-up continued measuring $\alpha \mathrm{FP}$ on a regular basis with gradually extending intervals (every 3 months in the second year, every 6 months in the third year and once a year in the fourth and fifth year). Clinical evaluation and abdominal

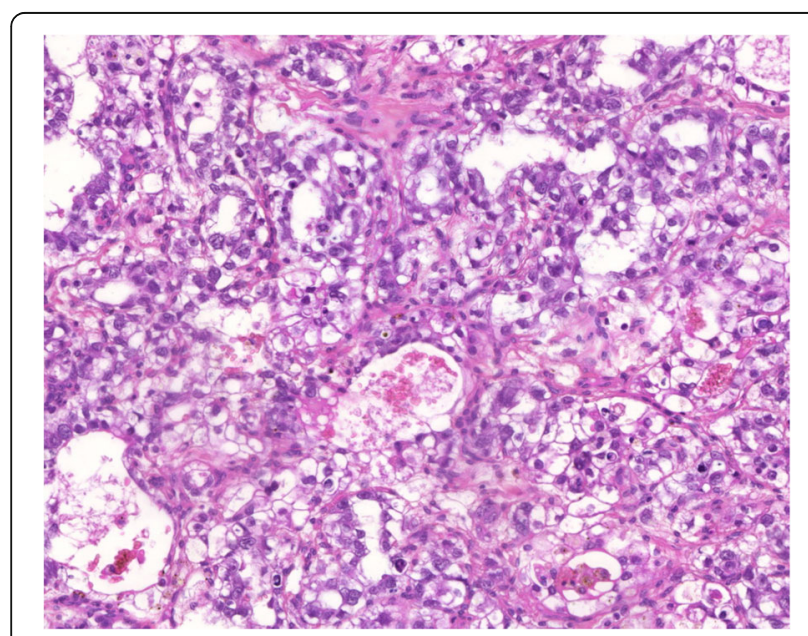

Fig. 1 Yolk sac tumor with a reticular pattern formed by a loose meshwork of spaces (10x)

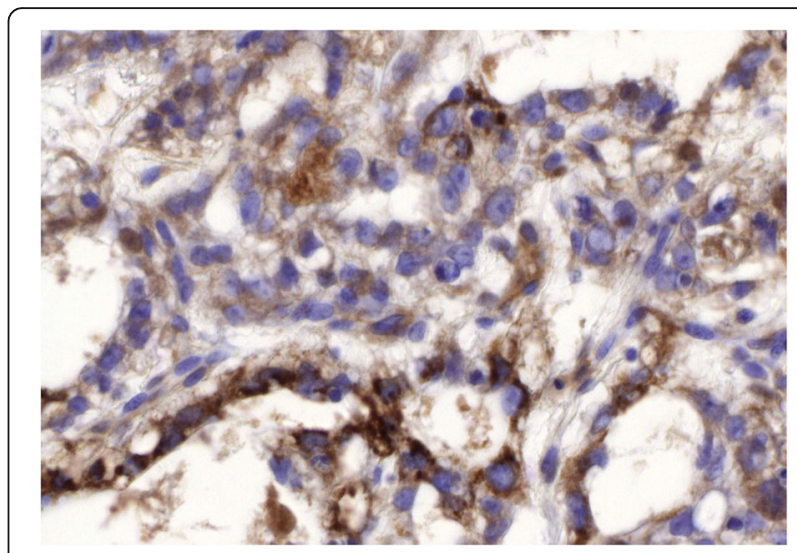

Fig. 2 Yolk sac tumor with strong cytoplasmic positivity for alphafetoprotein

ultrasound 5 years after the second resection showed a full tumor-free remission (Fig. 4). She was discharged from systematic follow-up.

\section{Discussion}

GCTs consist of neoplastic cells arising from germ line cells (egg or sperm). They occur either in the testis or
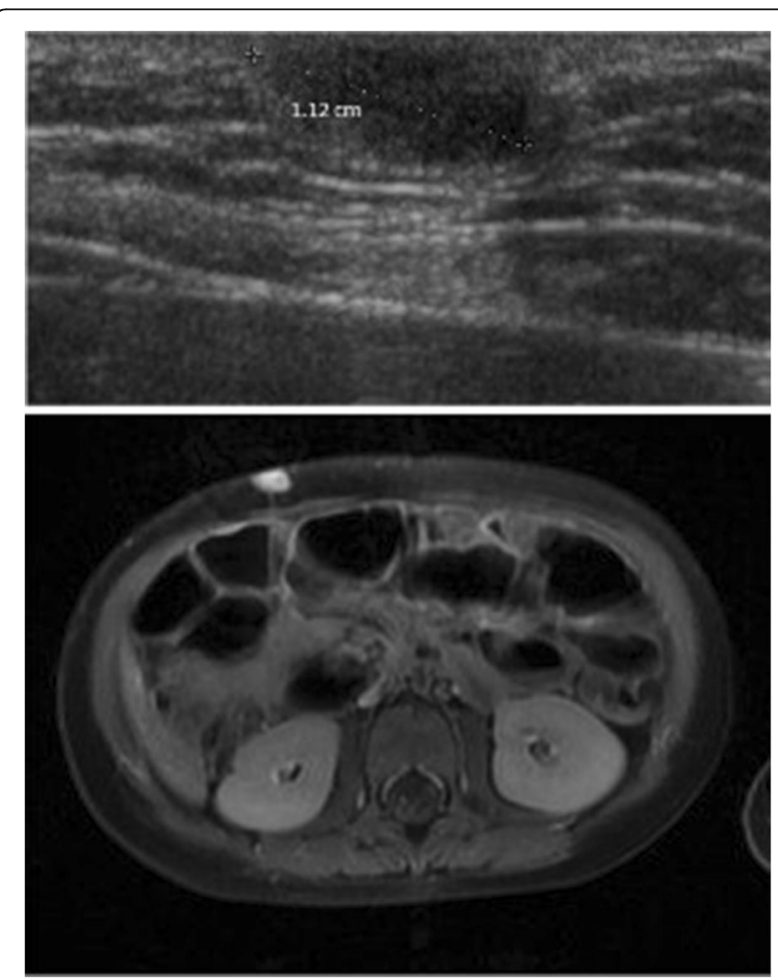

Fig. 3 Ultrasound of the abdominal wall showing a subcutaneous oval-shaped nodule, hyporeflective, and without clear margins. Abdominal magnetic resonance imaging (axial oblique T1-weighted with contrast) with a contrast-captivating nodule in the right abdominal wall 


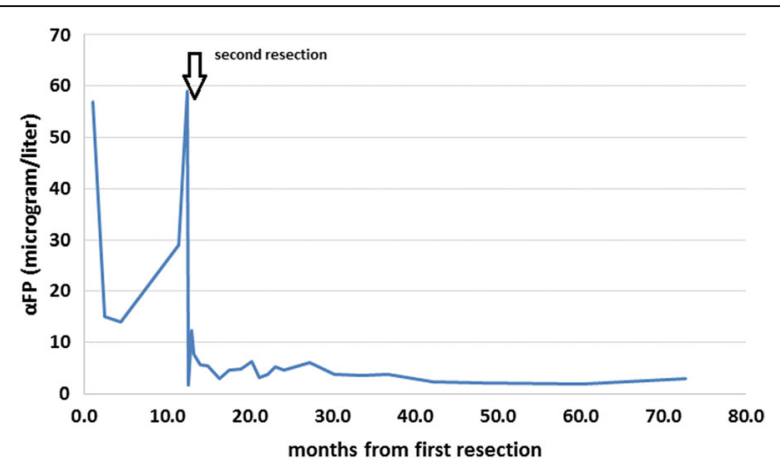

Fig. 4 The course of alpha-fetoprotein in time (months) after the first resection. The arrow represents the second resection. aFP alpha-fetoprotein

ovary, or outside the gonads. The extragonadal location is caused by either malignant transformation of aberrantly migrated primordial germ cell misplaced during the embryogenesis, or by a metastatic lesion of an undetected primary gonadal GCT not yet macroscopically visible or already spontaneously regressed. Extragonadal yolk sac tumors are rare and typically occur in midline locations, other sites have rarely been described [5]. Yolk sac tumors most often present in the first years of life and rarely with metastatic disease at diagnosis [6]. While age seems not to be a predictive factor, some authors describe the elevation of $\alpha \mathrm{FP}$ to be prognostically important [7]. The $\alpha \mathrm{FP}$ levels appear to correlate with the pathologic grade of retroperitoneal teratomas [8]. Without appropriate treatment, the tumor is highly aggressive, but with the combined treatment of surgery and adjuvant multi-agent platinum-based chemotherapy, a survival rate greater than $90 \%$ can be achieved. The currently used regimens have comparable efficacy: PEI (cisplatin, etoposide, ifosfamide); carboPEI (carboplatin, PEI); BEP (bleomycin, etoposide, cisplatin); and carboplatin, etoposide, bleomycin [9].

Billmire et al. studied 25 children with malignant GCTs of the abdomen and retroperitoneum as the primary site and examined survival and event-free survival rates using high-dose or standard-dose cisplatin-based combination chemotherapy and surgical resection for these patients [10]. Most tumors were of advanced stage at diagnosis and in 15 patients histology showed pure yolk sac tumor. Of the 25 patients, four patients had their primary site located at the abdominal wall [10]. Maubec et al. reported an overview of primary skin GCTs, 16 of the 19 patients were children, and a mature teratoma was the most frequent diagnosis [11]. Tedgündüz et al. described a 3-year-old girl with a subcutaneous paraspinal yolk sac tumor with metastatic disease located in the scar tissue at the surgical site and lumbar vertebrae. She received chemotherapy (cisplatin, etoposide, and bleomycin) and has been in remission for several years [12]. No other child with yolk sac tumor of the skin has been reported in the literature.

In yolk sac tumors, the tumor marker $\alpha \mathrm{FP}$ is extremely sensitive for diagnosis and in follow-up after the appropriate treatment has been given [13]. $\alpha \mathrm{FP}$ is an important serum binding protein in the fetus and is produced in the first trimester of fetal development by the yolk sac, afterwards by the fetal liver, and is gradually replaced by albumin. The $\alpha F P$ levels are usually highly elevated at birth with a significant variation in values among babies [14]. The half-life of $\alpha \mathrm{FP}$ is approximately 5 to 6 days and normal adult levels $(<10 \mathrm{IU} / \mathrm{l})$ are achieved by the age of 2 years. Even then a wide variation in levels is observed [14] and some suggest that a mild elevation in $\alpha \mathrm{FP}$ should not be used as the sole criterion to initiate or continue chemotherapy [15]. Therefore, in the first 2 years of life, $\alpha F P$ levels should be compared with age-related normal values. Serial measurements are necessary for optimal treatment decision. Most relapses occur within the first 2 years after diagnosis. Failure to normalize or a rise in the $\alpha \mathrm{FP}$ level indicates a recurrence or incomplete resection of the yolk sac tumor [16], even before this can be shown by imaging methods.

$\alpha \mathrm{FP}$ is regarded as a characteristic tumor marker of malignant GCTs and epithelial liver tumors. It is not tumor-specific. Elevated $\alpha \mathrm{FP}$ in the serum of a child is also associated with benign conditions, for example hepatic disorders, hereditary disorders (for example ataxia telangiectasia, tyrosinemia type 1), systemic lupus erythematosus, and other malignant tumors (for example hepatoblastoma, hepatocellular carcinoma, pancreaticoblastoma, retinoblastoma) [17].

In regards of the patient presented, after the first resection, it was decided to observe her closely and not perform a wide resection. After local recurrence with an elevated $\alpha \mathrm{FP}$, a wide resection was done. No distant primary disease was found. Despite the availability of highly effective chemotherapy, we decided to observe. If the tumor reoccurs, then effective therapy can still be given. Due to the localization and the elevation of $\alpha \mathrm{FP}$ we could easily perform intensive surveillance by monthly measurement of her $\alpha \mathrm{FP}$ and yearly ultrasound of her abdomen (watch-and-wait strategy).

\section{Conclusions}

We describe the first report of an 18-month-old girl diagnosed with a yolk sac tumor subcutaneously. A year after resection, she presented with local recurrence, which was treated with a wide resection only. Five years of follow-up did not reveal signs of local recurrence or distant disease. It is important that clinicians are aware that yolk sac tumor can present in an unusual extragonadal 
place. In some cases, conservative treatment can be carried out with careful monitoring of the patient and their $\alpha \mathrm{FP}$.

\section{Acknowledgements}

The authors extend their thanks to Prof. Moerman for reviewing the pathology (Pathology, Katholieke Universiteit Leuven, Belgium).

\section{Funding}

No funding was secured for this study.

\section{Availability of data and materials}

Data are available in the manuscript.

\section{Authors' contributions}

MA was responsible for collecting data and the writing of the manuscript, DV was responsible for writing of the manuscript, $\mathrm{AH}$ was responsible for collecting data, SD was responsible for collecting data and the writing of the manuscript, JWB was responsible for patient screening and supervised the writing of the manuscript. All authors read and approved the final manuscript.

\section{Competing interests}

The authors declare that they have no competing interests.

\section{Consent for publication}

Written informed consent was obtained from the patient's legal guardian(s) for publication of this case report and any accompanying images. A copy of the written consent is available for review by the Editor-in-Chief of this journal.

\section{Ethics approval and consent to participate}

The parents of the patient described in this case report agreed that information will be used for publication.

\section{Author details}

'Department of Pediatrics, ZNA Queen Paola Children's Hospital, Antwerp, Belgium. 'Department of Pediatric Surgery, ZNA Queen Paola Children's Hospital, Antwerp, Belgium. ${ }^{3}$ Department of Pediatrics, Heilig Hart Hospital, Lier, Belgium. ${ }^{4}$ Department of Pathology, ZNA Middelheim Hospital, Antwerp, Belgium. ${ }^{5}$ Department of Pediatric Hematology Oncology, UZ Brussel, Jette, Belgium.

Received: 20 July 2016 Accepted: 21 January 2017

Published online: 20 February 2017

\section{References}

1. Bernstein L, Smith M, Liu L. Germ cell trophoblastic and other gonadal neoplasms ICCC X 1975-2004. In: Ries L, Melbert D, Krapcho M, editors. SEER Cancer Statistics Review. Bethesda: National Cancer Institute; 2007. p. 125-37.

2. Bebb GG, Grannis Jr FW, Paz IB, Slovak ML, Chilcote R. Mediastinal germ cell tumor in a child with precocious puberty and Klinefelter syndrome. Ann Thorac Surg. 1998:66:547-8.

3. Hasle $\mathrm{H}$, Jacobsen BB. Origin of male mediastinal germ-cell tumours. Lancet. 1995:345:1046.

4. Cushing B, Giller R, Cullen JW, Marina NM, Lauer SJ, Olson TA, Rogers PC, Colombani P, Rescorla F, Billmire DF, et al. Randomized comparison of combination chemotherapy with etoposide, bleomycin, and either highdose or standard-dose cisplatin in children and adolescents with high-risk malignant germ cell tumors: a pediatric intergroup study -Pediatric Oncology Group 9049 and Children's Cancer Group 8882. J Clin Oncol. 2004:22:2691-700

5. Sudour-Bonnange H, Orbach D, Kalfa N, Fasola S, Patte C. Germ cell tumors in atypical locations: experience of the TGM 95 SFCE trial. J Pediatr Hematol Oncol. 2014;36:646-8.

6. Calaminus G, Schneider DT, Bokkerink JP, Gadner H, Harms D, Willers R, Gobel U. Prognostic value of tumor size, metastases, extension into bone, and increased tumor marker in children with malignant sacrococcygeal germ cell tumors: a prospective evaluation of 71 patients treated in the German cooperative protocols Maligne Keimzelltumoren (MAKEI) 83/86 and MAKEI 89. J Clin Oncol. 2003:21:781-6.

7. International Germ Cell Consensus Classification: a prognostic factor-based staging system for metastatic germ cell cancers. International Germ Cell Cancer Collaborative Group. J Clin Oncol. 1997;15:594-603.
8. Hunter CJ, Ford HR, Estrada JJ, Stein JE. Alpha-fetoprotein levels correlate with the pathologic grade and surgical outcomes of pediatric retroperitoneal teratomas. Pediatr Surg Int. 2009;25:331-6.

9. Gobel U, Calaminus G, Schneider DT, Schmidt P. Haas RJ. Management of germ cell tumors in children: approaches to cure. Onkologie. 2002;25:14-22.

10. Billmire D, Vinocur C, Rescorla F, Colombani P, Cushing B, Hawkins E, Davis M, London WB, Lauer S, Giller R, Children's Oncology G. Malignant retroperitoneal and abdominal germ cell tumors: an intergroup study. J Pediatr Surg. 2003;38:315-8. discussion 315-318.

11. Maubec E, Avril MF, Duvillard P, Leclere J, Cae AL, Crickx B, Theodore C. Mixed nonseminomatous germ cell tumor presenting as a subcutaneous tissue mass. Am J Dermatopathol. 2006;28:523-5.

12. Tekgunduz SA, Bozkurt C, Sahin G, Apaydin S, Oren AC, Balkaya E, Ertem AU. A subcutaneous paraspinal yolk sac tumor in a child. J Pediatr Hematol Oncol. 2014:36:e115-7.

13. Dallenbach P, Bonnefoi H, Pelte MF, Vlastos G. Yolk sac tumours of the ovary: an update. Eur J Surg Oncol. 2006;32:1063-75.

14. Blohm ME, Vesterling-Horner D, Calaminus G, Gobel U. Alpha 1-fetoprotein (AFP) reference values in infants up to 2 years of age. Pediatr Hematol Oncol. 1998;15:135-42

15. Albany C, Einhorn L. Pitfalls in management of patients with germ cell tumors and slight elevation of serum alpha-fetoprotein. J Clin Oncol. 2014; 32:2114-5.

16. Guo $\mathrm{YL}$, Zhang $\mathrm{YL}$, Zhu JQ. Prognostic value of serum alpha-fetoprotein in ovarian yolk sac tumors: A systematic review and meta-analysis. Mol Clin Oncol. 2015:3:125-32.

17. Schneider DT, Calaminus G, Gobel U. Diagnostic value of alpha 1fetoprotein and beta-human chorionic gonadotropin in infancy and childhood. Pediatr Hematol Oncol. 2001;18:11-26.

\section{Submit your next manuscript to BioMed Central and we will help you at every step:}

- We accept pre-submission inquiries

- Our selector tool helps you to find the most relevant journal

- We provide round the clock customer support

- Convenient online submission

- Thorough peer review

- Inclusion in PubMed and all major indexing services

- Maximum visibility for your research

Submit your manuscript at www.biomedcentral.com/submit
) Biomed Central 